\title{
Conceptual Foundations of a Cognitive Health Program for Hispanic Patients with Minor Neurocognitive Disorder
}

\author{
Jorge A. Herrera Pino ${ }^{1,2}$, Jose Armas ${ }^{1}$, Nora Dieguez ${ }^{1}$, Eduardo Alarcon ${ }^{1}$ \\ ${ }^{1}$ Medical Care Consortium, Inc. (MCCI), Miami, USA. \\ ${ }^{2}$ Herbert Wertheim College of Medicine, Florida International University, Miami, USA \\ Email: jherreramdphd@gmail.com
}

Received July $27^{\text {th }}$, 2013; revised September $1^{\text {st }}$, 2013; accepted September $22^{\text {nd }}, 2013$

\begin{abstract}
Copyright (C) 2013 Jorge A. Herrera Pino et al. This is an open access article distributed under the Creative Commons Attribution License, which permits unrestricted use, distribution, and reproduction in any medium, provided the original work is properly cited.
\end{abstract}

\begin{abstract}
The purpose of this paper is to present the conceptual foundations used in the development of a cognitive health program for Hispanic patients who report memory concerns or complaints to their primary care physicians. These models are drawn from the field of neuropsychology, both as a professional endeavor and as a scientific discipline. This program has been developed based on prevailing models of higher cerebral functions, addressing primarily attention, memory, and executive functions. The role of neuropsychologists as active participants in the improvement of the cognitive status of the patients referred to them is not only emphasized in this article as going much beyond the diagnostic process, but also having an active participation in the subsequent treatment process. The models of attention that have served as the bases for the MCCI COGNITIVE HEALTH PROGRAM are those developed by Allan F. Mirsky and Michael I. Posner, while the memory model used is authored by Alan Baddeley. The two models of executive functions that are employed in the development of this program are those of Russell Barkley and Elkonon Goldberg. This program was also very much anchored on the concept of cognitive reserve and the work of Yaakov Stern was incorporated into the models used for the development of the program. The program is implemented in two phases. Patients referred by their primary care physicians undergo a functional neuropsychological evaluation to determine the nature and extent of their memory impairments. The results obtained in these evaluations are interpreted using the models referred to above. A treatment plan is developed and the program is implemented through the use of computer assisted cognitive rehabilitation procedures. The advantages of using computer assisted procedures are discussed in this article.
\end{abstract}

Keywords: Mild Cognitive Impairment; Minor Neurocognitive Disorder; Cognitive Reserve; Cognitive Rehabilitation; Attention; Memory; Executive Functions

\section{Introduction}

The practice of neuropsychology in the United States has seen a substantial increase in the past 20 years. However, by and large, neuropsychologists have played a much more prevalent role in the diagnosis of disorders of brain-behavior relationship, as opposed to participating directly in the remediation or correction of identified deficits. The purpose of this paper is to share with the professional community the foundations and implementation of a program of direct intervention based on solid neuropsychological principles and procedures, in which the participation of neuropsychologists is at its core.

Cognitive decline often seen in elderly individuals has been a focus of attention of scientific and medical literature for more than two decades (Albert et al., 2013). In many instances, prior to the identification of a definitive or at least probable dementia, what has been described as cognitive slippage, and subsequent cognitive decline, leading to mild cognitive impairment is identified. This is characterized by complaints made by patients oftentimes to their primary care physicians. Unfortunately, in many instances, these professionals are not available for their patients any form of intervention that may delay, to a significant degree, the onset of functional decline.

Cognizant of this situation, many healthcare institutions have begun implementing measures aimed at assisting their patients during these initial phases of what may eventually convert into a dementing disorder, manifested through significant decline in functions. For the past eight years, the MEDICAL CARE CONSORTIUM, INC. (MCCI), has implemented the MCCI COGNITIVE HEALTH PROGRAM, aimed at providing its primary care physicians with an effective intervention tool designed to alleviate and slow down the cognitive decline associated with mild cognitive impairment.

The term mild cognitive impairment, introduced initially by Petersen (Petersen, 2004; Petersen et al., 2001; Petersen et al., 1999) has been substituted recently by the term minor neurocognitive disorder in the fifth edition of the Diagnostic and Statistical Manual of Mental Disorders of the American Psychiatric Association (DSM-5; APA, 2013). To this effect, this is the term, which will be used to describe the patients that currently participate in the MCCI COGNITIVE HEALTH PROGRAM discussed in this paper. 


\section{Medical Care Consortium, Inc. (MCCI)}

MCCI is a full coverage multi-center organization that provides health care services to a variety of patients. MCCI out-patient centers are staffed by both primary care physicians and specialists. Patients who report difficulties or complaints with memory and cognitive functions are referred to the MCCI COGNITIVE HEALTH PROGRAM for diagnosis and treatment of minor neurocognitive disorder. Patients seen in the MCCI centers in Metropolitan Miami-Dade County, Florida, are primarily Hispanic and their native and preferred language is Spanish.

\section{Conceptual Models of Brain Functioning}

The MCCI COGNITIVE HEALTH PROGRAM is based on a number of conceptual models of brain functioning. Following please find a description of the conceptual models of brain functioning that have served as the foundations for this program.

American neuropsychology, following initially the tradition established by authors such as Ward C. Halstead, Ralph M. Reitan, Philip M. Rennick, and others, followed what has been described to be an actuarial model of interpretation, in contra position to a heuristic model. However, as time has passed, a number of very important theoretical positions have been developed by renowned authors in the field of brain-behavior relationship. Salient among these are the contributions of Allan F. Mirsky and colleagues of the National Institutes of Mental Health in regards to the process of attention.

According to Mirsky et al. (Mirsky, 1987; Mirsky \& Duncan, 2001; Mirsky et al., 1991), attention is not a unitary process, but rather, it can be broken down into at least four sub-processes. The first of these is the ability to focus and execute efficiently. According to these authors, this is the component of attention which opens the door to cognitive processing. Being able to attend to relevant stimuli or to relevant aspects of specific stimuli, is a necessary prerequisite, if attention is going to be used effectively. The second function which Mirsky et al. (Mirsky, 1987; Mirsky \& Duncan, 2001; Mirsky et al., 1991) include in their model of attention is being able to sustain it over time. Again, if the focusing and executing efficiently component is put into effect, it needs to remain active for the time that is necessary for attention to actually be useful.

This model of attention includes a third component, which has to do with coding information into working memory so that the process of learning can take place. Once the individual has attended to relevant stimuli or to relevant aspects of stimuli and sustained attention sufficient time for learning or coding to take place, the focus of attention has to be shifted to meet new environmental demands which require the individual to adapt. Thus, the fourth and final component of attention presented by Mirsky et al. (Mirsky, 1987; Mirsky \& Duncan, 2001; Mirsky et al., 1991) is that of shifting attention adaptively and resisting the ever present tendency to perseverate, experienced by individuals who somehow have attentional impairments.

Another model of attention, which goes beyond that proposed by Mirsky et al. (Mirsky, 1987; Mirsky \& Duncan, 2001; Mirsky et al., 1991), has been described by Michael I. Posner from the University of Oregon. This model introduces an "executive" component to the process of attention. According to Posner et al. (Posner \& Rothbart, 2007; Rueda, Posner, \&
Rothbart, 2005), paying attention implies a decision making process which directs attention adaptively to relevant stimuli or relevant aspects of stimuli present in the environment. Michael I. Posner has been reported as saying something to the effect that "we see with our occipital lobes, but we look with our frontal lobes" in reference to "executive attention" (Rothbart \& Posner, 2005).

The implication is that attention is not only "vigilance". That is, being alert or awake. Attention implies being able to direct it appropriately within the concept of "orientation”. According to Posner et al. (Rothbart \& Posner, 2005) there is often a conflict between that which you habitually pay attention to and that which you need to pay attention to, in order to function adaptively. Posner's model of attention has been widely validated by neuro-radiological studies (cf. Kübler, Dixon, \& Garavan, 2006; Talati \& Hirsch, 2005).

Once attention has done its job and it has been used to further adaptation to the demands of the environment, the process that has been described as "working memory" needs to take place. The model of working memory chosen for the MCCI COGNITIVE HEALTH PROGRAM described in this article is the one developed by Alan Baddeley, formerly of Bristol University and currently of York University in the United Kingdom. According to Baddeley's model (Baddeley, 2003, 2010, 2007), information is usually processed through two different avenues in order to become incorporated into memory. The first mechanism described by Baddeley (2003) is the "phonological loop". Through this process, information is "rehearsed" verbally to facilitate it becoming part of memory.

The next mechanism of working memory posed by Baddeley (2007) is the "visual scratch pad". This is an eidetic memory process through which information becomes part of working memory by being able to be "visualized".

It is quite interesting to note that the two mechanisms of acquisition of working memory posed by Baddeley (2007) are very consistent with the concepts proposed by authors like Ralph M. Reitan and others regarding the "functional asymmetry of the brain" (Reitan, 1955). One of the most important early discoveries of the research conducted by Reitan (Reitan, 1966) in the Neuropsychology Laboratory of Indiana University, was the fact that there was a definite identifiable set of cognitive impairments associated with right hemisphere damage.

Other contemporary authors (cf. Funka et al., 2010; Karnath, Rorden, \& Ticini, 2009) have identified the mechanisms underlying a phenomenon seen frequently in neurologically impaired patients with right hemisphere damage. This is the presence of left visual field neglect. This symptom is seen very frequently in patients who have sustained some form of cerebrovascular accident affecting the right hemisphere.

Once the information is stored into memory, it serves as the basis for planning, organizing, and carrying out action. This process has been described abundantly in the neuropsychological literature and given the name "executive functions". Two models of executive functions have served as the bases for the MCCI COGNITIVE HEALTH PROGRAM described in this article. These have been developed respectively by Russell Barkley of the Medical University of South Carolina and Elkonon Goldberg of the New York University School of Medicine.

The model developed by Barkley $(1997,2001)$ proposes that, before action is implemented in response to a given situation 
that arises in the environment, an inhibitory process must be put in place in order to allow sufficient time for executive functions to modulate the response. This inhibitory process of the "prepotent behavior" allows the individual to produce a more adaptive response.

The four executive functions proposed by Barkley (1997; 2001) are non-verbal working memory, which allows the individual to recollect similar situations confronted in the past, verbal working memory, which refers to guidance provided by internalized language, self-regulation of affect, emotion, and arousal, as well as what Barkley $(1997,2001)$ referred to as reconstitution. All of these processes are brought to bear on the decision the individual will make when confronted with a specific situation or problem.

Goldberg (2002, 2009), on the other hand, proposed a model of executive functions very much in line with what Alexandr R. Luria (1972) had referred to as Functional Unit III of the brain. Included in these processes are the intention, the planning, and the execution of behavior, as well as the process of monitoring its consequences. Goldberg (2002, 2009) also makes emphasis on higher level cognitive processes, such as concept formation and abstraction.

One final conceptual framework used as the basis for the MCCI COGNITIVE HEALTH PROGRAM described in this article, was developed by Yaakov Stern of the Columbia University Medical Center (Stern, 2002, 2006). The concept of "cognitive reserve" has become increasingly popular and widely accepted in the past decade. At the root of this concept is the notion that there are many things that can be done through an individual's life in order to strengthen cognitive abilities as a protective factor to cognitive decline in later life.

The concept of cognitive reserve is fundamental to the development and implementation of the MCCI COGNITIVE HEALTH PROGRAM. Cognitive reserve was initially seen within the context of a "passive model". This implied that constitutional or genetic protective factors were responsible for delaying the onset of functional deterioration in dementing processes. Authors such as Alexander et al. (1997) studied premorbid intellectual functioning as a strong contributor to cognitive reserve, if not the most important one.

Other authors, such as Mori et al. (1997) posited that constitutional factors, such as brain size, were responsible for "reserve capacity” against intellectual decline in dementing disorders, such as Alzheimer's disease.

Stern (2002) acknowledges the "passive model” of cognitive reserve in his seminal paper. However, he presents a much more "active model" of cognitive reserve, which, in turn, is divided into two different approaches. The first approach focuses on the development of cognitive reserve in order to enhance cognition within a "normative" framework. That is, according to this view, there are things that individuals can do to enhance their cognition and to become more resistant to the onset of functional deterioration.

There is no question that cognitive reserve can be built up during the person's developmental cycle. However, the question arises regarding the possibility of improving cognitive reserve if there already is brain pathology, as is definitely suspected in minor neurocognitive disorder. To this effect, the second approach proposed by Stern (2002) for the development of cognitive reserve already presupposes the presence of brain pathology. It seeks to "compensate" for cognitive decline by stimulating and activating alternative circuits or neural net- works, in order to perform the same function that is in peril of becoming impaired. It also proposes that previously inactive portions of the cortex can be recruited in order to improve brain activity and functional efficiency. This point of view has been subsequently expanded and clarified by Stern (Stern, 2006, 2009) and Stern et al. (2003).

There has recently been an accumulation of research and studies found in contemporary neuropsychological literature that strengthens the notion that cognitive intervention or rehabilitation implemented during the initial phases of a progressive dementing disorder can delay the onset of functional deterioration. To this effect, Vasile (2013) very aptly described this phenomenon: "Exercising the memory and the desire of understanding the environment, together with a proper relationship with it, is probably one of the strongest factors generating cognitive reserve" (2013: p. 604). This seems to be particularly well suited for patients with minor neurocognitive disorder.

\section{Neuropsychological Evaluation}

Patients that participate in the MCCI COGNITIVE HEALTH PROGRAM are initially referred by their primary care physicians, usually due to having reported memory difficulties. Upon referral, an initial neuropsychological diagnostic interview is conducted by a doctoral level neuropsychologist. In addition to gathering pertinent information as to the nature and onset of the memory complaints, the patients' present medication regime, as well as the presence of any systemic or psychiatric condition, the patients are administered the Mini-Mental Status Examination (Folstein, Folstein, \& McHugh, 1975; Folstein et al. 2001, 2002)).

Subsequent to that, a neuropsychological evaluation of the patients is conducted, including the following instruments: Test de Inteligencia No-Verbal 2 (Brown, Sherbenou, \& Johnsen, 2000) or Test of Non-Verbal Intelligence 4 (Brown, Sherbenou, \& Johnsen,, 2010), Symbol Digit Modalities Test (Smith, 1973, 1982, 2002), Controlled Oral Word Association Test (Lezak, Howieson, \& Loring, 2004; Spreen \& Strauss, 1998), Rey Osterrieth Complex Figure Test (Rey, 2003; Meyers \& Meyers, 1995), Rey Auditory Verbal Learning Test (Schmidt, 1996), Boston Naming Test (Kaplan, Goodglass, \& Weintraub, 1983, 1996), Benton Visual Retention Test (Benton, 1974, 2002; Sivan, 1992), Grooved Pegboard Test (Lafayette Instrument Company Model 32025), Beck Anxiety Inventory (Beck \& Steer, 1993), and Geriatric Depression Scale (Yesavage et al., 1983).

If the patients' primary language is Spanish, as is the case with Hispanic patients, the authorized Spanish language editions of the neuropsychological instruments is used and administered by Spanish speaking neuropsychologists. The results obtained by the patients in these instruments are analyzed following the parameters of double dissociation of function developed by Hans-LukasTeuber (Walsh, 1985) and the axes of interpretation proposed by Manfred Meier (1974). These processes allow for the identification of impairments following the conceptual models described above and the development of a treatment plan within the framework of "restorative" cognitive rehabilitation, as described in the paragraphs that follow.

\section{Cognitive Rehabilitation}

Neuropsychologists have traditionally conducted evaluations of brain-behavior relationships. These evaluations often result 
in recommendations for interventions for other disciplines, such as occupational and speech and language therapy, as well as different specialists in education. In the MCCI COGNITIVE HEALTH PROGRAM, the role of the neuropsychologist has been extended much beyond the process of evaluation. Based on the knowledge of brain-behavior relationship, which is inherent to the training of the neuropsychologist, direct procedures of intervention have been put in place stemming directly from this knowledge and expertise, through the implementation of an active "restorative" cognitive rehabilitation program.

Cognitive rehabilitation has become part and parcel of the treatment options now available to patients with minor neurocognitive disorders and its conceptual and practical dimensions are the focus of on-going research (cf. Huckans et al., 2013). Among the success obtained using cognitive rehabilitation procedures is the reduction of "conversion" of patients with mild cognitive impairment (now minor neurocognitive disorder) to dementia (Rojas et al., 2013) and the improvement of recall in patients with dementia (Smith, 2013).

There are two primary models of cognitive rehabilitation, which are widely implemented currently. There is "compensatory" cognitive rehabilitation, which seeks to provide the patients with alternative means to put into practice a particular cognitive function. For instance, providing patients with a notebook to write down information, to avoid forgetting it, is a common way of implementing "compensatory" cognitive rehabilitation.

Other examples of this approach would be the establishment of a fixed schedule of activities to be carried out as part of well established routines, or making sure that objects are placed always in the same place to facilitate later retrieval. Formulating verbally an intention before carrying out an action and to be able to remember what the patients have come to do or get when they arrive somewhere, is another example of "compensatory" cognitive rehabilitation.

The other model of cognitive rehabilitation has been described as "restorative" in nature. It is essentially a neuropsychological model, which proposes to identify where in a particular function the process has become impaired and subsequently to implement a series of well thought out and planned exercises to, in effect, restore the function. The approach chosen for the MCCI COGNITIVE HEALTH PROGRAM described in this article is restorative in nature. This approach to cognitive rehabilitation favors the use of computerized technology.

In this regard, there have been for many years now a number of computer software suites specifically designed to improve cognitive functioning. However, within the conceptual framework of the MCCI COGNITIVE HEALTH PROGRAM described in this article, rather than favoring one or another of these suites, certain criteria have been established for their inclusion in it.

In the first place, any computerized suite of cognitive rehabilitation exercises included in this program must provide the clinicians a wide range of exercises to choose from, addressing the different functions covered by the models upon which the MCCI COGNITVE HEALTH PROGRAM is based, as described above. Exercises included in the suite must go from being able to help the patients develop a quicker and more accurate response to stimuli, being able to focus attention and executing more efficiently, all the way to the development of the ability to abstract, form concepts, and regulate behavior. Evidently, if anyone suite of programs cannot cover this wide range of cognitive abilities, exercises from different suites are integrated into the overall MCCI COGNITIVE HEALTH PROGRAM.

Another important feature of the exercises found in anyone computerized or software suite is the ability to present them with high-frequency. Restorative cognitive rehabilitation has been predicated on the need for abundant repetition (LeónCarrión, 2010). This was nearly impossible to do at the rate that exercises can be presented now, prior to the advent of the personal computer. Restorative cognitive rehabilitation requires high-frequency presentation of stimuli within relatively short periods of time.

Being able to provide patients with accurate and immediate feedback regarding the appropriateness of their responses, both in terms of correct and incorrect responses is another key feature necessary for a suite of computerized cognitive exercises. It is also important that the patients involved in the program maintain their motivation. In this regard, the clinicians in charge should make sure that $60 \%$ of the responses made by the patients are correct, and that appropriate feedback is given. The other $40 \%$ of the exercises should present a challenge for the patients and feedback on correct and incorrect responses is immediately received.

Any suite of software exercises used in restorative cognitive rehabilitation should also provide very accurate information on a number of parameters that indicate if indeed there is progress or not. For instance, the very basic attentional process of focusing and executing, described by Mirsky et al. (Mirsky, 1987; Mirsky \& Duncan, 2001; Mirsky et al., 1991) depends very much on the length of the reaction time of the patients. It is very important that any suite of computerized exercises that is employed in a program is capable of providing the clinicians with adequate and accurate information regarding the reaction time of the patients and if, indeed, it is shortened as a result of the procedures implemented in the program.

Another measure that has been found to be very informative regarding the progress of the patients is the difficulty level of the exercises. As the patients progress through their treatment, their performance within a certain level of difficulty improves. To this effect, an initial ratio of success of $60 / 40 \%$ should progress to $70 / 30 \%$, and subsequently to $80 / 20 \%$. The experience gathered in the implementation of the MCCI COGNITIVE HEALTH PROGRAM described in this article has shown that, if the success to challenge ratio goes beyond $80 / 20 \%$, motivation decreases, as the exercise becomes more a matter of routine. On the other hand, if this ratio is $50 / 50 \%$ or below, patients run the risk of losing motivation. This highlights the need for the suite of computerized exercises used to have clearly demarcated difficulty levels, so that patients can be moved from easier to more difficult levels as the treatment progresses.

Although in the MCCI COGNITIVE HEALTH PROGRAM a number of different suites of computerized cognitive exercises are used, as noted earlier, the one suite of programs that has been found to best meet the criteria mentioned above is PSSCogRehab (Bracy, 1994). This suite of programs has a recently developed new version (Bracy, 2012), which is also available in Spanish.

\section{Implementation of the MCCI Cognitive Health Program}

Subsequent to the neuropsychological evaluation, a treatment 
plan is designed individually for each patient following the framework of the conceptual models of brain functioning described above. It is important to note that the diagnostic process implemented in the MCCI COGNITIVE HEALTH PROGRAM is not nosological in nature. That is, it does not necessarily focus on the etiology of the condition presented by the patients. As a matter of fact, mild cognitive impairment until recently, and only after becoming minor neurocognitive disorder, was not considered a diagnosis as such.

The diagnostic process followed in the MCCI COGNITIVE HEALTH PROGRAM is "functional" in nature. For instance, if it is determined that the patients showed impairment in the basic attentional process of focusing and executing, a very frequent finding in elderly individuals who report difficulties with memory processes, an assessment is made of their reaction time, which may by now be increased, not allowing information to be stored into memory for later retrieval. The experience obtained throughout these eight years shows that reaction time is susceptible to training, and once it is reduced, memory difficulties reported by the patients are substantially decreased.

There are patients who present specific difficulties with other cognitive functions, such as incorporating information through the "phonological loop" described above. The use of computerized exercises allows the clinicians working with these patients to set up conditions under which abundant rehearsal and a concerted effort at developing the patients' metacognitions regarding this process has a restorative effect and the memory complaints subside.

Restorative cognitive rehabilitation in the MCCI COGNITIVE HEALTH PROGRAM is delivered on a one to one basis in which each patient works directly with a clinician. Given the intensive nature of this procedure, it has been found that 45 minutes sessions conducted twice per week yield the most benefit for the patients. Sessions are programmed in multiples of 12, with reassessment at the end of each 12 session cycle.

Outcome measures obtained during the implementation of the program with specific patients usually include reaction time, ratio of correct to incorrect responses, difficulty level of the exercises presented, as well as progress up and down the ladder of cognitive functions, beginning with basic attentional processes and moving to executive functions, again, within the framework of the conceptual models the program is based on. Reduction of symptoms of memory impairment is assessed every session using an ascending subjective rating scale ranging from 0 to 10 . Overall average reduction of symptoms obtained in this scale is 8 points in this scale..

\section{Conclusion}

The purpose of this paper is to show that neuropsychology, as a science and as a profession, can have a definite role, not only in the diagnosis of neurological disorders, but also in their management and treatment. This practice is theoretically supported by the emerging concepts of cognitive reserve and cognitive rehabilitation. Clinicians and researchers in this field of professional and scientific endeavor are encouraged to pursue the role of the neuropsychologist in the restoration of cognitive functions, in addition to furthering the knowledge of the efficacy of restorative cognitive rehabilitation procedures and interventions through research focusing on out-come measures and neuro-radiological evidence of change. The decrease of the rate of conversion from minor neurocognitive disorder to de- mentia is another important research avenue to be pursued.

\section{REFERENCES}

Albert, M., Dekowsky, S. T., Dickson, D., Dubois, B., Feldman, H. H., Fox, N. C., Gamst, A., Holtzman, D. M., Jagust, W. J., Petersen, R. C., Sneyder, P. J., Carrillo, M. C., Thies, B., \& Phelps, C. H. (2013). The diagnosis of mild cognitive impairment due to Alzheimer's disease: Recommendations from the National Institute on Aging-Alzheimer's Association's Workgroups on Diagnostic Guidelines for Alzheimer's Disease. FOCUS, 11, 96-106. http://dx.doi.org/10.1176/appi.focus.11.1.96

Alexander, G. E., Furey, M. L, Grady, C. L., Pietrini, P., Brady, D. R., Mentis, M. I., \& Shapiro, M. B. (1997). American Journal of Psychiatry, 154, 165-172.

American Psychiatric Association (2013). Diagnostic and statistical manual of mental disorders ( $5^{\text {th }}$ ed.). Washington DC: American Psychiatric Association.

Barkley, R. A. (2001). The executive functions and self-regulation: An evolutionary neuropsychological perspective. Neuropsychology Review, 11, 1-29. http://dx.doi.org/10.1023/A:1009085417776

Barkley, R. A. (1997). Behavioral inhibition, sustained attention, and executive functions: Constructing a unifying theory of ADHD. Psychological Bulletin, 121, 65-94. http://dx.doi.org/10.1037/0033-2909.121.1.65

Baddeley, A. (2010). Working memory. Current Biology, 20, R136R140. http://dx.doi.org/10.1016/j.cub.2009.12.014

Baddeley, A. (2007). Working memory, thought, and action. New York: Oxford University Press.

http://dx.doi.org/10.1093/acprof:oso/9780198528012.001.0001

Baddeley, A. (2003). Working memory and language: An overview. Journal of Communication Disorders, 36, 189-208. http://dx.doi.org/10.1016/S0021-9924(03)00019-4

Beck, A. T., \& Steer, R. (1993). Beck anxiety inventory. San Antonio (TX): The Psychological Corporation.

Benton, A. L. (2002). Test de retención visual de Benton: Manual (5th ed.). Madrid: TEA Ediciones, S.A.

Benton, A. L. (1974). Revised visual retention test (4th ed.). New York: The Psychological Corporation.

Bracy, O. (2012). PSSCogRehab 2012. Indianapolis (IN): Psychological Software Services, Inc.

Bracy, O. (1994), PSSCogRehab. Indianapolis (IN): Psychological Software Services, Inc.

Brown, L., Sherbenou, R. J., \& Johnsen, S. K. (2010). TONI-4. Test of Non-Verbal Intelligence 4. Austin (TX): PRO-ED.

Brown, L., Sherbenou, R. J., \& Johnsen, S. K. (2000). TONI-2. Test de Inteligencia No-Vetbal 2. Madrid: TEA Ediciones, S.A.

Folstein, M. F., Folstein, S. E., McHugh, P. R., \& Fanjiang, G. (2002). MMSE Examen Cognoscitivo Mini-Mental. Madrid: TEA Ediciones, S.A.

Folstein, M. F., Folstein, S. E., McHugh, P. R., \& Fanjiang, G. (2001). Mini-mental status examination. Odessa (FL): Psychological Assessment Resources.

Folstein, M. F., Folstein, S. E., \& McHugh, P. R. (1975). Mini-Mental State: A practical guide for grading the cognitive state of patients for the clinician. Journal of Psychiatric Research, 12, 189-198. http://dx.doi.org/10.1016/0022-3956(75)90026-6

Funka, J., Finkea, K., Müllera, H. J., Utzb, K. S., \& Kerkhoffc, G. (2010). Effects of lateral head inclination on multimodal spatial orientation judgments in neglect: Evidence for impaired spatial orientation constancy. Neuropsychologia, 48, 1616-1627. http://dx.doi.org/10.1016/j.neuropsychologia.2010.01.029

Goldberg, E. (2009). The new executive brain: Frontal lobes in a complex world. New York: Oxford University Press.

Goldberg, E. (2002). The executive brain: Frontal lobes and the civilized mind. New York: Oxford University Press.

Huckans, M., Hutson, L., Twamley, E., Jak, A., Kaye, J., \& Storzbach, D. (2013). Efficacy of cognitive rehabilitation therapies for mild cogni- tive impairment (MCI) in older adults: Working toward a theoretical model and evidence-based interventions. Neuropsychol- 
ogy Review, 23, 63-80. http://dx.doi.org/10.1007/s11065-013-9230-9

Kaplan, E. F., Goodglass, H., \& Weintraub, S. (1996). Test de vocabulario de Boston ( $2^{\text {nd }}$ ed.). Buenos Aires: Editorial Médica Panamericana.

Kaplan, E. F., Goodglass, H., \& Weintraub, S. (1983). The Boston naming test ( $2^{\text {nd }}$ ed.). Philadelphia (PA): Lea \& Febiger.

Karnath, H. O, Rorden, C., \& Ticini, L. F. (2009). Damage to white matter fiber tracts in acute spatial neglect. Cerebral Cortex, 19, 2331-2337. http://dx.doi.org/10.1093/cercor/bhn250

Kübler, A., Dixon, V., \& Garavan, H. (2006). Automaticity and reestablishment of executive control-An f MRI study. Journal of Cognitive Neuroscience, 18, 1331-1342.

http://dx.doi.org/10.1162/jocn.2006.18.8.1331

Lezak, M. D. Howieson, D. D., \& Loring, D. W. (2004). Neuropsychological assessment (4th ed.). New York: Oxford University Press.

León Carrión, J. (2010). Rehabilitación neuropsicológica del daños cerebral. Mente y Cerebro, 45, 62-71.

Luria, A. R. (1972). The working brain: An introduction to neuropsychology. New York: Basic Books.

Meier, M. J. (1974). Some challenges for clinical neuropsychology. In R. M. Reitan, \& L. A. Davison (Eds.), Clinical neuropsychology: Current status and applications. New York: John Wiley \& Sons.

Meyers, J. E., \& Meyers, K. R. (1995). Rey complex figure test and recognition trial. Odessa (FL): Psychological Assessment Resources.

Mirsky, A. F. (1987). Behavioral and psychophysiological markers of disordered attention. Environmental Health Perspectives, 74, 191199. http://dx.doi.org/10.1289/ehp.8774191

Mirsky, A. F., \& Duncan, C. C. (2001). A nosology of disorders of attention. Annals of the New York Academy of Sciences, 931, 17-32. http://dx.doi.org/10.1111/j.1749-6632.2001.tb05771.x

Mirsky, A. F., Anthony, B. J., Duncan, C. C., Ahearn, M. B., \& Kellam, S. C. (1991). Analysis of the process of attention: A neuropsychological approach. Neuropsychology Review, 2, 109-145. http://dx.doi.org/10.1007/BF01109051

Mori, E., Hirono, N., Yamashita, H., Imamura, T., Ikejiri, Y., Ikeda, M., Kitagaki, H., Shimomura, T., \& Yukihiro Y (1997). Premorbid brain size as a determinant of reserve capacity against intellectual decline in Alzheimer's disease. American Journal of Psychiatry, 154, 18-24.

Petersen, R. C. (2004). Mild cognitive impairment as a diagnostic entity. Journal of Internal Medicine, 256, 183-194. http://dx.doi.org/10.1111/j.1365-2796.2004.01388.x

Petersen, R. C., Doody, R., Kurz, A., Mohs, R. C., Morris, J. C. Rabins, P. V., Ritchie, K., Rossor, M., Leon Thal, L., \& Winblad, B. (2001). Current concepts in mild cognitive impairment. Archives of Neurology, 58, 1985-1992. http://dx.doi.org/10.1001/archneur.58.12.1985

Petersen, R. C., Smith, G. E., Waring, S. C., Ivnik, R. J., Tangalos, E. G., \& Kokmen, E. (1999). Mild cognitive impairment: Clinical characterization and outcome. Archives of Neurology, 56, 303-308. http://dx.doi.org/10.1001/archneur.56.3.303

Posner, M. I., \& Rothbart, M. K. (2007). Educating the human brain. Washington DC: American Psychological Association. http://dx.doi.org/10.1037/11519-000

Rothbart, M. K., \& Posner, M. I. (2005). Genes and experience in the development of executive attention and effortful control. New Directions for Child and Adolescent Development, 109, 101-108. http://dx.doi.org/10.1002/cd.142

Reitan, R.M. (1966) A research program on the psychological effects of brain lesions on human beings. In N. R. Ellis (Ed.), International re- view of research in mental retardation (pp. 156- 214). New York: Academic Press.

Reitan, R. M. (1955). Certain differential effects of left and right cerebral lesions in human adults. Journal of Comparative and Physiological Psychology, 48, 474-477. http://dx.doi.org/10.1037/h0048581

Rey, A. (2003). Test de copia y reproducción de memoria de figuras complejas (8th ed.). Madrid: TEA Ediciones, S.A.

Rojas, G. J., Villar, V., Iturry, M., Harris, P., Serrano, C. M., Herrera, J. A., \& Allegri, R. A. (2013). Efficacy of a cognitive intervention program in patients with mild cognitive impairment. International Psychogeriatrics, 25, 824-831. http://dx.doi.org/10.1017/S1041610213000045

Rueda, M. R., Posner, M. I., \& Rothbart, M. K. (2005). The development of executive attention: Contributions to the emergence of selfregulation. Developmental Neuropsychology, 28, 573-594. http://dx.doi.org/10.1207/s15326942dn2802_2

Schmidt, M. (1996). Rey auditory verbal learning test: A handbook. Los Angeles, CA: Western Psychological Services.

Sivan, A. B. (1992). Benton visual retention test (5th ed.). San Antonio, TX: The Psychological Corporation.

Smith, A. (2002). SDMT: Test de símbolos y dígitos. Madrid: TEA Ediciones, S.A.

Smith, A. (1982). Symbol Digit Modalities Test. Los Angeles, CA: Western Psychological Services.

Smith, A. (1973). Symbol Digit Modalities Test. Los Angeles, CA: Western Psychological Services.

Smith, J. A. (2013). Recall of event information following memory training in Alzheimer's disease. Clinical Gerontologist, 36, 316-328. http://dx.doi.org/10.1080/07317115.2013.788119

Spreen, O., \& Strauss, E. (1998). A compendium of neuropsychological tests (2nd ed.). New York: Oxford University Press.

Stern, Y. (2009). Cognitive reserve. Neuropsychologia, 47, 2015-2028. http://dx.doi.org/10.1016/j.neuropsychologia.2009.03.004

Stern, Y. (2006). Cognitive reserve and Alzheimer's disease. Alzheimer's Disease and Associated Disorders, 20, 112-117. http://dx.doi.org/10.1097/01.wad.0000213815.20177.19

Stern, Y (2002). What is cognitive reserve? Theory and research application of the reserve concept. Journal of the International Neuropsychological Society, 8, 448-460. http://dx.doi.org/10.1017/S1355617702813248

Stern, Y., Zarahn, E., Hilton, J., Flynn, J., De La Paz, R., \& Rakitin, B. (2003). Exploring the neural basis of cognitive reserve. Journal of Clinical and Experimental Neuropsychology, 25, 5, 691-701. http://dx.doi.org/10.1076/jcen.25.5.691.14573

Talati, A., \& Hirsch, J. (2005). Functional specialization within the medial frontal gyrus for perceptual go/no-go decisions based on "what," "when," and where" related information: An fMRI study. Journal of Cognitive Neuroscience, 17, 981-993. http://dx.doi.org/10.1162/0898929054475226

Vasile, C. (2013). Cognitive reserve and cortical plasticity. ProcediaSocial and Behavioral Sciences, 78, 601-604. http://dx.doi.org/10.1016/j.sbspro.2013.04.359

Walsh, K.W. (1985). Understanding brain damage. A primer of neuropsychological evaluation. Edinburgh: Churchill Livingstone.

Yesavage. J. A., Brink, T. L., Rose, T. L., et al. (1983). Development and validation of a geriatric depression screening scale: A preliminary report. Journal of Psychiatric Research, 17, 37-49. http://dx.doi.org/10.1016/0022-3956(82)90033-4 